\title{
Associations between long-term exposure to air pollution, glycosylated hemoglobin and diabetes
}

\author{
Trenton Honda ${ }^{1}{ }^{,}$, Vivian C. Pun ${ }^{1}$, Justin Manjourides ${ }^{1}$, and Helen Suh ${ }^{2}$ \\ ${ }^{1}$ Department of Health Sciences, Northeastern University, 202 Robinson Hall, 360 Huntington \\ Ave, Boston, MA 02115 \\ ${ }^{2}$ Department of Civil and Environmental Engineering, Tufts University, Medford, MA
}

\begin{abstract}
BACKGROUND—Air pollution exposures have been shown to adversely impact health through a number of biological pathways associated with glucose metabolism. However, few studies have evaluated the associations between air pollution and glycosylated hemoglobin (HbA1c) levels. Further, no studies have evaluated these associations in US populations or investigated whether associations differ in diabetic as compared to non-diabetic populations. To address this knowledge gap, we investigated the associations between airborne fine particulate matter $\left(\mathrm{PM}_{2.5}\right)$ and nitrogen dioxide $\left(\mathrm{NO}_{2}\right)$ and $\mathrm{HbAlc}$ levels in both diabetic and non-diabetic older Americans. We also examined the impact of $\mathrm{PM}_{2.5}$ and $\mathrm{NO}_{2}$ on prevalent diabetes mellitus (DM) in this cohort.
\end{abstract}

METHODS-We used multilevel logistic and linear regression models to evaluate the association between long-term average air pollutant levels and prevalence of DM and HbA1c levels, respectively, among 4,121 older (57+ years) Americans enrolled in the National Social Life, Health, and Aging Project between 2005 and 2011. All models adjusted for age, sex, body mass index, smoking status, race, household income, education level, neighborhood socioeconomic status, geographic region, urbanicity and diabetic medication use. We estimated participantspecific exposures to $\mathrm{PM}_{2.5}$ on a six-kilometer grid covering the conterminous U.S. using spatiotemporal models, and to $\mathrm{NO}_{2}$ using nearest measurements from the Environmental Protection Agency's Air Quality System. HbA1c levels were measured for participants in each of two data

*Corresponding author. t.honda@northeastern.edu.

Publisher's Disclaimer: This is a PDF file of an unedited manuscript that has been accepted for publication. As a service to our customers we are providing this early version of the manuscript. The manuscript will undergo copyediting, typesetting, and review of the resulting proof before it is published in its final citable form. Please note that during the production process errors may be discovered which could affect the content, and all legal disclaimers that apply to the journal pertain.

DUALITY OF INTEREST: The authors declare that there is no duality of interest associated with this manuscript.

CONTRIBUTION STATEMENT: TH, VP, JM and HS were involved in the data management, analysis, interpretation and drafting the manuscript. All authors reviewed/edited the manuscript and approved the final version.

Ethics approval and consent to participate: This study was approved by the institutional review board (IRB) of Northeastern University and all participants provided written informed consent: IRB\# 13-07-18

Consent for publication: Not Applicable.

Availability of data and material: The data that support the findings of this study are available from the National Social Life, Health and Aging Project (NSHAP) but restrictions apply to the availability of these data, which were used under license for the current study, and so are not publicly available. Data are however available from the authors upon reasonable request and with permission of NSHAP.

Competing Interests: The authors declare that they have no competing interests. 
collection waves from dried blood spots and log-transformed prior to analysis. Participants were considered diabetic if they had HbA1c values $\geq 6.5 \%$ or reported taking diabetic medication.

RESULTS-The prevalence of diabetes at study entry was $22.2 \%(\mathrm{n}=916)$ and the mean HbA1c was $6.0 \pm 1.1 \%$. Mean one-year moving average $\mathrm{PM}_{2.5}$ and $\mathrm{NO}_{2}$ exposures were $10.4 \pm 3.0 \mu \mathrm{g} / \mathrm{m}^{3}$ and $13.1 \pm 7.0 \mathrm{ppb}$, respectively. An inter-quartile range (IQR, $3.9 \mu \mathrm{g} / \mathrm{m}^{3}$ ) increase in one-year moving average $\mathrm{PM}_{2.5}$ was positively associated with increased diabetes prevalence (prevalence odds ratio, POR 1.35, 95\% CI: 1.19, 1.53). Similarly, an IQR (8.6 ppb) increase in $\mathrm{NO}_{2}$ was also significantly associated with diabetes prevalence (POR $1.27,95 \%$ CI: $1.10,1.48)$. $\mathrm{PM}_{2.5}(1.8 \%$ $\pm 0.6 \%, \mathrm{p}<0.01)$ and $\mathrm{NO}_{2}(2.0 \% \pm 0.7 \%, \mathrm{p}<0.01)$ exposures were associated with higher $\mathrm{HbA} 1 \mathrm{c}$ levels in diabetic participants, while only $\mathrm{NO}_{2}$ was significantly associated with $\mathrm{HbA} 1 \mathrm{c}$ in nondiabetic participants $(0.8 \% \pm 0.2 \%, \mathrm{p}<0.01)$. Significant dose response relationships were identified for both pollutants in diabetic participants and for $\mathrm{NO}_{2}$ in non-diabetic participants.

CONCLUSIONS/INTERPRETATIONS-In a cohort of older men and women in the United States, $\mathrm{PM}_{2.5}$ and $\mathrm{NO}_{2}$ exposures were significantly associated with prevalence of DM and increased $\mathrm{HbA} 1 \mathrm{c}$ levels among both non-diabetic and diabetic participants. These associations suggest that air pollution could be a key risk factor for abnormal glucose metabolism and diabetes in the elderly.

\section{Keywords}

Air pollution; diabetes; glycosylated hemoglobin; elderly

\section{INTRODUCTION}

Air pollution exposures have been shown to adversely impact health through a number of biological pathways, including: Oxidative and endoplasmic reticulum stress, systemic and visceral adipose tissue inflammation, and endothelial and mitochondrial dysfunction (Rajagopalan and Brook, 2012; Sun et al., 2009; van Eeden et al., 2001). These pathways have, in turn, been shown to contribute to abnormal insulin signaling and/or increased insulin resistance in skeletal muscle, both of which are characteristic of type 2 diabetes mellitus (DM) (Rajagopalan and Brook, 2012; Sun et al., 2009).

While some epidemiologic evidence suggests air pollution may be linked with DM, this evidence is inconsistent. Small positive associations for prevalence of DM have been observed with nitrogen dioxide $\left(\mathrm{NO}_{2}\right)$ (Andersen et al., 2012; Brook et al., 2008; Coogan et al., 2012; Eze et al., 2014; Kramer et al., 2010; Park et al., 2015) and fine particulate matter $\left(\mathrm{PM}_{2.5}\right)$ (Chen et al., 2013; Eze et al., 2014; Kramer et al., 2010; Liu et al., 2016; Park et al., 2015; Pearson et al., 2010) while other studies have found no significant associations (Brook et al., 2008; Dijkema et al., 2011; Puett et al., 2011). Associations between air pollution and serum glucose, a measure of glucose homeostasis used to assess diabetes status, have been investigated in a few studies which have reported links between short-term $\mathrm{NO}_{2}$ exposure and small increases in serum glucose (0.40\%, 95\% CI: 0.31\%, 0.50\%) (Sade et al., 2015), with larger associations observed for short-term $\mathrm{PM}_{2.5}$ exposures and serum glucose in diabetic individuals (2.93\%, 95\% CI: 0.35\%, 5.59\%) (Yitshak Sade et al., 2016). Since serum glucose can vary widely over short periods of time, it is not an ideal outcome measure 
for assessing the potential effects of long-term pollution exposures. To address this, glycosylated hemoglobin (HbA1c), a marker of long-term glucose control, has been investigated in limited studies (Chuang et al., 2010; Liu et al., 2016; Yitshak Sade et al., 2016). These studies have shown significant increases in HbAlc associated with higher $\mathrm{PM}_{2.5}$ exposures in Chinese and Israeli populations, while null associations were observed in a recent German cohort (Wolf et al., 2016). No prior studies of air pollution and HbA1c have been conducted in US populations. To address this gap, we evaluate the association of $\mathrm{PM}_{2.5}$ and $\mathrm{NO}_{2}$ with prevalence of DM and $\mathrm{HbA} 1 \mathrm{c}$ levels in a nationally representative cohort of older (57+ years) Americans.

\section{METHODS}

\section{Population}

The National Social Life, Health, and Aging Project (NSHAP) is a prospective, population based probability sample of 4,121 older (57+ year), community-dwelling Americans selected from eligible households identified in the Health and Retirement Study (HRS) in 2004 (Waite et al., 2014; Waite LJ, 2014). The survey over-sampled African-Americans, Latinos, men and the oldest old (75-84 years). In total, 3,005 participants were recruited in Wave 1 (2005-2006) and 3,377 in Wave 2 (2010-2011). Response rates for each wave were high, with $75 \%$ and $74 \%$ of individuals selected for Wave 1 and Wave 2 opting to participate, respectively. Of the Wave 2 participants, 2,261 also participated in Wave 1, while 744 from Wave 1 were either too sick to participate in Wave 2 or deceased. Additional Wave 2 participants were selected from eligible respondent $(n=907)$ and non-respondent $(n=209)$ households originally identified from the HRS probability sample. Participants in each wave underwent in-person interviews to obtain demographic (age, sex, race), social (education level) behavioral (physical activity, tobacco and alcohol use) and health data (history of diagnosed medical conditions and/or medication use), including that on self-reports of physician diagnosed diabetes and use of diabetes and cardiovascular medication. The questions and interview instruments were essentially unchanged between the two waves (Waite et al., 2014; Waite LJ, 2014). At the time of the interviews, biomeasure data on anthropometrics, cardiovascular and physical health, and blood spots were also collected. The study protocol was approved by the Institutional Review Boards of Northeastern University and the University of Chicago; all participants provided written informed consent.

\section{Exposure assessment}

$\mathrm{PM}_{2.5}$ exposure was estimated on a six-kilometer $(\mathrm{km})$ grid covering the United States obtained from spatio-temporal generalized additive mixed models (GAMMs). Models were based on the daily $\mathrm{PM}_{2.5}$ mass from 1999-2007 as reported previously in Yanosky et al. (Yanosky et al., 2014). Briefly, the U.S. Environmental Protection Agency (EPA) Air Quality System (AQS) database and Interagency Monitoring of Protected Visual Environments (IMPROVE) network provided daily $\mathrm{PM}_{2.5}$ data (EPA, 2009; IMPROVE, 2013). Spatio-temporal models were developed incorporating wind speed, temperature and total precipitation as meteorological covariates and county population density, point-source $\mathrm{PM}_{2.5}$ emissions density, land use, line-source estimated traffic-related $\mathrm{PM}_{2.5}$, and elevation 
as geospatial covariates. Daily $\mathrm{PM}_{2.5}$ estimates were then used to calculate 1-5 year moving average exposure windows. $\mathrm{PM}_{2.5}$ estimates were subsequently validated using crossvalidation techniques, with a cross-validation $\mathrm{R}^{2}$ of 0.76 (Yanosky et al., 2014). Exposures were assigned to NSHAP participants based on the grid point closest to their residential address. The distance between each grid centroid-residential address pair varied between $0.05 \mathrm{~km}$ and $4.21 \mathrm{~km}$, with a mean distance of $2.23 \mathrm{~km}$.

Exposures to nitrogen dioxide $\left(\mathrm{NO}_{2}\right)$ for each NSHAP participant were estimated using measurements from the nearest AQS monitor within $80 \mathrm{~km}$ of their residential address (202 individual monitors). Exposure windows of one to five year moving averages from the date of interview were calculated for $\mathrm{PM}_{2.5}$ and $\mathrm{NO}_{2}$. Moving averages were considered valid if $\geq 75 \%$ of the daily values within each exposure window were available. For both pollutants, the moving averages were calculated backwards from the date of study enrollment. All NSHAP participants had valid $\mathrm{PM}_{2.5}$ measurements for each exposure window, while for $\mathrm{NO}_{2}$, the number of participants with valid exposures varied by exposure window, ranging between $79.4 \%$ of participants having valid $\mathrm{NO}_{2}$ measures for the five-year exposure window to $81.5 \%$ for the one-year exposure window. As estimated exposures and residential addresses were assessed in each wave, changes in residence between waves were accounted for in assigning exposure estimates for both $\mathrm{PM}_{2.5}$ and $\mathrm{NO}_{2}$ models.

\section{Outcome Assessment}

HbA1c was collected via dried blood spots on filter paper. HbA1c measurements obtained using dried blood spots have previously been shown to be highly correlated with those obtained using venous blood draws (Lacher et al., 2013; Parkes et al., 1999). For Wave 1, blood spots were analyzed for HbA1c using the Roche Unimate immunoassay and Cobas Inegra Analyzer. For Wave 2, HbA1c assays were conducted using automated ion-exchange high-performance liquid chromatography (IE-HPLC) performed on a Bio-Rad Variant II Hemoglobin Testing System. Both methods are National Glycohemoglobin Standardization Program (NGSP) certified, and between-wave differences in NSHAP HbA1c measurements have been shown to be comparable to those observed in other large, national studies (Gregg et al., 2014).

Blood spot collection was randomized to five out of six Wave 1 participants ( $\mathrm{N}=2494)$ (Nallanathan, 2008); 389 of the selected participants opted out of the blood spot collection. Wave 1 participants who did and did not provide blood spots did not differ significantly with respect to sex, race/ethnicity, age, educational attainment, income level, or reported physical health (Nallanathan, 2008). Due to collection and/or analytic problems, HbA1c measurements were not available for an additional 359 Wave 1 participants. In sum, a total of 1,746 Wave 1 participants (70.0\%) and 3,037 Wave 2 participants (89.9\%) had valid $\mathrm{HbA1c}$ measurements. A maximum of two measurements was available per participant.

DM was defined in dichotomous models as one or more of the following: 1) HbA1c $\geq 6.5 \%$, or 2) Participant self-reported taking anti-diabetic medication in one or more of the following categories: alpha-glucosidase inhibitors, anti-diabetic combinations, insulin, miscellaneous anti-diabetic agents, and/or sulfonylureas. 


\section{Covariates}

We evaluated potential confounding and effect modification using wave-specific covariates. Body mass index (BMI) was calculated as weight in kilograms divided by height in meters squared. Race/ethnicity was categorized as White, Black, Hispanic or other. Socioeconomic status was assessed on an individual level using self-reported educational attainment (categorized as: 1) less than a high school education, 2) high school graduate or equivalent, 3) some college, and 4) bachelor's degree or greater) and was assessed on a neighborhood level using median census track household income and percent of households living below the poverty line from the 2000 U.S. Census. Smoking status was categorized as current, historical or none. Physical activity was classified based on the frequency of self-reported, exercise as follows: 1) never, 2) less than one time per month, 3) 1-2 times per week, 4) 3-4 times per week, and 5) 5 or more times per week. Participants were additionally classified based on the region in which they lived (North Atlantic, South, Great Lakes region, Plains States, Pacific) as well as the relative urbanicity of their place of residence (Categorized into the following six levels [1) 12 largest Standard Metropolitan Statistical Areas (SMSAs) 2) 13-100 largest SMSAs, 3) 12 largest suburbs, 4) 13-100 largest suburbs, 5) Other urban, 6) Other rural]. Data completeness for covariates was high, with $6.3 \%$ missingness for BMI and less than $5 \%$ of participants with missing data on all other covariates.

\section{Statistical Analysis}

We used linear regression models accounting for repeated measures with random intercepts at the level of the participant to examine the association between log-transformed $\mathrm{HbA} 1 \mathrm{c}$ and an interquartile range (IQR) increase in one to five year moving averages of $\mathrm{PM}_{2.5}$ and $\mathrm{NO}_{2}$. Regression coefficients were anti-log transformed and the percent changes are presented. Models were run for the entire cohort and separately for non-diabetic and diabetic participants. Models incorporated inverse-probability weights to account for non-response and oversampling of some demographic groups. Dose-response relationships were assessed using indicator variables for quartiles of exposure and dose-response smoothing curves. To examine the impact of $\mathrm{PM}_{2.5}$ and $\mathrm{NO}_{2}$ exposures on prevalent $\mathrm{DM}$ as a dichotomous outcomes, we also ran logistic models accounting for repeated measures and inverse probability weighted for non-response and oversampling. All models controlled for confounders selected based upon their previous associations with diabetes or air pollution (Andersen et al., 2012; Brook et al., 2008; Chen et al., 2013; Coogan et al., 2012; Dijkema et al., 2011; Kramer et al., 2010; Pearson et al., 2010; Puett et al., 2011). Fully-adjusted linear models controlled for BMI, age, sex, race, education, current and historical tobacco use, geographic region of residence (indicator variables for five regions), one of six levels of urbanicity, physical activity and for neighborhood socioeconomic status using census track data on median household income and percent of households living below the poverty line. Use of diabetic medication was controlled for in linear models for diabetic participants, as diabetic medication use is an important predictor of HbAlc levels and is also potentially associated with air pollutant exposures, since it indicates access to healthcare (a measure of socioeconomic status potentially associated with pollution exposures). We investigated the independent effects of $\mathrm{NO}_{2}$ and $\mathrm{PM}_{2.5}$ and their joint effects using two-pollutant models. 
Since some covariates could modify the effect of pollution (Andersen et al., 2012; Park et al., 2015), we also examined interaction terms between air pollutants and sex, smoking status, BMI and age. Missing data for covariate and outcome variables in all models were imputed by multiple imputation chained equations to create ten datasets with complete data. Parameter and variance estimates for each of the data sets was then combined for inference using standard procedures (White et al., 2011). Smoothing spline functions were plotted using complete cases.

We conducted several sensitivity analyses. First, to examine the impact of exposure error, we redefined $\mathrm{NO}_{2}$ exposures to include only those participants living within $60 \mathrm{~km}, 40 \mathrm{~km}, 20$ $\mathrm{km}$, and $10 \mathrm{~km}$ of $\mathrm{NO}_{2}$ monitors. Second, logistic models with a more restrictive (based on $\mathrm{HbA} 1 \mathrm{c} \geq 6.5 \%$ only) and a more inclusive (defined as HbA1c $\geq 6.5 \%$, on anti-diabetic medication or self-reports a history of DM) definition of DM were investigated. Third, to ensure bias was not introduced by imputation, we conducted complete-case analyses. Statistical analyses were completed using SAS Version 9.4 (SAS INC, Cary, NC).

\section{RESULTS}

Characteristics of the study participants can be found in Table 1 . The average age of participants at study entry was 69.6 years. Upon entering the study, $53.7 \%$ of the participants were female and 916 of the 4121 (22.6\% of the total participants) were diabetic. The majority $(80.3 \%)$ of diabetic participants reported actively taking at least one anti-diabetic medication. Compared to those without DM, those with DM at study entry had a higher BMI $\left(31.9 \mathrm{~kg} / \mathrm{m}^{2}\right.$ versus $\left.28.5 \mathrm{~kg} / \mathrm{m}^{2}, \mathrm{p}<0.001\right)$ were more likely to be Black ( $24.5 \%$ versus $13.4 \%, \mathrm{P}<0.001)$ or Hispanic (14.6\% versus $9.6 \%, \mathrm{p}<0.001)$, have low educational attainment $(\mathrm{p}<0.001)$ and low levels of physical activity $(\mathrm{p}<0.001)$. Median household incomes were lower for those with DM $(\$ 49,231$ versus $\$ 55,696, \mathrm{p}<0.001)$, and diabetic participants lived in census tracks with a higher percentage of residents below the poverty line (17.7\% versus $14.0 \%, \mathrm{p}<0.001)$. Correlations between $\mathrm{PM}_{2.5}$ and $\mathrm{NO}_{2}$ varied from $\mathrm{r}=0.30$ for one-year moving averages to $\mathrm{r}=0.33$ for five-year moving averages.

\section{Glycosylated hemoglobin: Full cohort analysis}

In the full cohort (including both non-diabetic and diabetic participants), an IQR increase in one-year moving average $\mathrm{PM}_{2.5}\left(3.9 \mu \mathrm{g} / \mathrm{m}^{3}\right)$ was associated with a $1.4 \% \pm 0.3 \%$ higher $\mathrm{HbA1c}$ while an IQR increment increase in $\mathrm{NO}_{2}(8.6 \mathrm{ppb})$ was associated with a $2.0 \%$ $\pm 0.3 \%$ higher HbA1c (Table 2). For both of these associations, significant effect modification by diabetes status was identified $\left(\mathrm{PM}_{2.5} \mathrm{P}_{\text {interact }}<0.001, \mathrm{NO}_{2} \mathrm{P}_{\text {interact }}=0.015\right)$. Associations were thus further investigated in non-diabetic and diabetic participants separately.

\section{Glycosylated hemoglobin and air pollution: Non-diabetic participants}

In non-diabetic participants, an IQR increase in one-year moving average $\mathrm{PM}_{2.5}$ was not significantly associated with higher $\mathrm{HbA1c}(0.2 \% \pm 0.2 \%$, Table 2$)$. For $\mathrm{NO}_{2}$, we found positive, significant associations in non-diabetic participants, with an IQR increase in $\mathrm{NO}_{2}$ associated with $0.8 \% \pm 0.2 \%$ ( $<<0.001)$ higher HbA1c levels. Significant dose-response was 
also observed for $\mathrm{NO}_{2}$ in examination of exposures quartiles (p-trend=0.028) and investigation of smooth dose-response curves (Figure 1). Associations were stable and essentially unchanged for longer-term (2-5 year) moving averages of both pollutants (Table $3)$.

\section{Glycosylated hemoglobin and air pollution: Diabetic participants}

In diabetic participants, the magnitude of the associations with HbA1c was larger than that in non-diabetics (Table 2), with an IQR increase in $\mathrm{PM}_{2.5}$ and $\mathrm{NO}_{2}$ associated with $\mathrm{HbA1c}$ $1.8 \% \pm 0.6 \%(\mathrm{p}<0.01)$ and $2.0 \% \pm 0.7 \%(\mathrm{p}<0.01)$ higher, respectively. Dose response relationships were identified for both pollutants, with the highest observed association for $\mathrm{PM}_{2.5}$ in the fourth quartile of exposure $(2.8 \% \pm 1.2 \%$, p-trend=0.002) while the largest association for $\mathrm{NO}_{2}$ was observed in the third quartile $(2.9 \% \pm 1.4 \%$, p-trend=0.032). Spline curves demonstrate no significant deviations from linearity for either pollutant (Figure 2, Figure 3). For longer term moving averages (2-5 year) the associations for $\mathrm{PM}_{2.5}$ diminished in magnitude, while those for $\mathrm{NO}_{2}$ remained relatively stable (Table 3 ).

\section{Diabetes prevalence and air pollution}

Consistent with our findings for $\mathrm{HbAlc}$, we found an IQR increase in one-year average $\mathrm{PM}_{2.5}$ to be associated with $35 \%$ increased prevalence-odds of DM (Prevalence odds ratio, POR 1.35 95\% CI: 1.19, 1.53) when diabetes status was treated as a dichotomous outcome. Positive, significant associations were observed for all moving averages, although the observed association was strongest for one-year exposures (Table 4). Significant effects were also observed for $\mathrm{NO}_{2}$, with an IQR increase in one-year moving average associated with higher odds of DM (POR 1.27, 95\% CI: 1.10, 1.48). Longer-term (2-to-5 year) moving averages of both $\mathrm{PM}_{2.5}$ and $\mathrm{NO}_{2}$ remained positively associated with DM prevalence, although the magnitudes of association were somewhat diminished.

\section{Two-pollutant models and effect modification}

In two-pollutant models (incorporating both $\mathrm{NO}_{2}$ and $\mathrm{PM}_{2.5}$ ), one-year average $\mathrm{NO}_{2}$ remained significantly associated with HbA1c in both non-diabetic and diabetic participants, while the effect estimates of one-year average $\mathrm{PM}_{2.5}$ were not significant (Supplement table 1). In two-pollutant logistic models, one year moving averages of both $\mathrm{NO}_{2}(\mathrm{POR} 1.17,95 \%$ CI: $1.00,1.36$ ) and $\mathrm{PM}_{2.5}$ (POR 1.27, 95\% CI: 1.10, 1.46) were significantly associated with DM prevalence, although the POR for $\mathrm{NO}_{2}$ was attenuated. No significant effect modification was observed either linear or logistic models (data not shown).

Sensitivity analyses were conducted to evaluate the possibility of exposure error for $\mathrm{NO}_{2}$ models (Supplement Table 2). Models limited to those living within $60 \mathrm{~km}, 40 \mathrm{~km}, 20 \mathrm{~km}$ and $10 \mathrm{~km}$ showed similar, positive associations to those we observed for our main models. In models of diabetic participants, however, standard errors of the effect estimates increased, reducing the statistical significance of the associations when models were limited to individuals living within $20 \mathrm{~km}$ ( $\mathrm{p}=0.054)$ and especially $10 \mathrm{~km}$ ( $\mathrm{p}=0.076$ ) of a monitoring site. This increase in standard errors is likely explained by the smaller sample sizes included in these analyses. In prevalence models limited to $60 \mathrm{~km}, 40 \mathrm{~km}, 20 \mathrm{~km}$ and $10 \mathrm{~km}$, we also observed consistent effect estimates across the various distances. As above, models limited 
to $10 \mathrm{~km}$ from a monitor had similar effect estimates but became non-significant ( $\mathrm{p}=0.091$ ), likely due to the decreased samples size in this analyses.

Further sensitivity analyses were undertaken to examine whether multiple imputation introduced bias. Linear complete case analyses in non-diabetic $\left(\mathrm{NO}_{2}: 0.6 \% \pm 0.02 \%\right.$, $\left.\mathrm{p}=0.007 ; \mathrm{PM}_{2.5}: 0.1 \% \pm 0.2 \%, \mathrm{p}=0.468\right)$ and diabetic $\left(\mathrm{NO}_{2}: 2.7 \% \pm 1.0 \%, \mathrm{p}=0.006 ; \mathrm{PM}_{2.5}\right.$ : $2.1 \% \pm 0.7 \%, \mathrm{p}=0.006)$ participants demonstrated similar associations to those from our imputed results. Our findings were further robust to specification of an alternative, more restrictive definition of diabetes (based solely on $\mathrm{HbA1c}$ level $¥ 6.5 \%$ ), as well as a more inclusive definition (defined as HbA1c $\geq 6.5 \%$, on anti-diabetic medication or self-reports a history of DM, Supplement Table 3).

\section{DISCUSSION}

In our nationally representative sample of older, community-dwelling Americans, we found an IQR increase in one-year $\mathrm{PM}_{2.5}$ and $\mathrm{NO}_{2}$ exposures to be significantly associated with increases in $\mathrm{HbA} 1 \mathrm{c}$ and diabetes prevalence. In non-diabetic participants, $\mathrm{NO}_{2}$ exposures were significantly associated with $0.8 \% \pm 0.2 \%$ higher $\mathrm{HbA} 1 \mathrm{c}$ levels, while $\mathrm{PM}_{2.5}$ exposures were null. In diabetic participants, significant associations of considerably larger magnitude were observed for both $\mathrm{PM}_{2.5}(1.8 \% \pm 0.6 \%, \mathrm{p}<0.01)$ and $\mathrm{NO}_{2}(2.0 \% \pm 0.7 \%, \mathrm{p}<0.01)$. Dose-response relationships were also identified for both pollutants in diabetic participants, but only for $\mathrm{NO}_{2}$ in non-diabetic participants. Correspondingly, prevalence-odds of DM was $35 \%$ higher (95\% CI: 19\%, 53\%) in those with higher $\mathrm{PM}_{2.5}$ exposures, and $27 \%$ higher ( $95 \%$ CI: $10 \%, 48 \%$ ) in those with increased $\mathrm{NO}_{2}$ exposures. The associations for both pollutants and both outcomes were generally strongest for one-year moving averages, with longer term averages (three to five year) associated with attenuated effect estimates. As longer-term moving averages of $\mathrm{NO}_{2}$ exposures had different sample sizes of participants with valid exposures, it is important to note that this may impact the comparability of findings across the various moving averages.

Interestingly, we observed that the associations of air pollutant exposures on HbAlc levels were stronger in diabetics as compared to non-diabetics. This is consistent with previous studies reporting that DM increases susceptibility to the deleterious effects of air pollution, possibly through systemic inflammatory pathways (O’Neill et al., 2007). Consistent with these reports, chronic systemic inflammation has been shown to increase insulin resistance and perhaps impair pancreatic beta cell insulin secretion, both of which would lead to impaired glucose control and, ultimately, elevations in HbA1c (King, 2008). As type 2 diabetes has been found to have both genetic as well as precipitating environmental factors (Poulsen et al., 1999), individuals with DM may be particularly susceptible to further perturbations in metabolic pathways by increased exposure to air pollution. Previous studies have observed that the risk of diabetic complications increases with poor glucose control, with significant increases in risk of macrovascular and microvascular complications occurring at HbA1c levels $>7.0 \%$ and $>6.5 \%$, respectively (Zoungas et al., 2012). While much of the previous literature examining the effects of air pollution has concentrated on DM risk, our findings suggest that air pollution may also have a significant impact on glucose control among diabetics and thus risk of DM complications. As the population 
burden of diabetes in the united states is high (29.1 million persons with DM in the US as of 2012 , with medical costs over $\$ 245$ billion (CDC, 2014) even small associations with air pollution exposures may be of significant public health importance.

Our findings are consistent with results from previous studies showing significant impacts of $\mathrm{PM}_{2.5}$ and $\mathrm{NO}_{2}$ on DM prevalence in US populations. A 2010 U.S. ecological study, for example, found a significant association between estimated $\mathrm{PM}_{2.5}$ exposure and county-level estimates of DM prevalence in the US, with a $10 \mu \mathrm{g} / \mathrm{m}^{3}$ increase in $\mathrm{PM}_{2.5}$ associated with a $1 \%$ increase in DM prevalence (Pearson et al., 2010). Correspondingly, a recent study of Multi-Ethnic Study of Atherosclerosis participants $(\mathrm{N}=5,839)$ found significant positive associations between an IQR increase in $\mathrm{PM}_{2.5}\left(2.43 \mu \mathrm{g} / \mathrm{m}^{3}\right)$ and DM prevalence (OR 1.09, 95\% CI: $1.00,1.17$ ) and $\mathrm{NO}_{2}$ (IQR: $47.1 \mathrm{ppb}$ ) and DM prevalence (OR 1.18, 95\% CI: 1.01 , 1.38) (Park et al., 2015). While we found somewhat higher associations for DM prevalence in our study, it is important to note that our study population is significantly older than these prior US studies, making our population potentially more susceptible to air pollution's deleterious effects. As prevalence of DM is consistently higher in older populations ( $>65$ years) (Wild et al., 2004), It is possible that much of the difference in association between our study and prior US literature is due to the higher average age of the NSHAP cohort.

In non-US cohorts, findings have been less consistent. A recent study of DM prevalence by Liu et al. (2016) in a large ( $\mathrm{n}=11,847)$, Chinese population reported significant, positive associations per IQR $\left(41.1 \mu \mathrm{g} / \mathrm{m}^{3}\right.$ ) increase in $\mathrm{PM}_{2.5}$ (Prevalence Ratio 1.14, 95\% CI: 1.08 , 1.20) (Liu et al., 2016), as did a 2014 study of 6,392 Swiss participants which examined 10year moving averages of $10 \mu \mathrm{g} / \mathrm{m}^{3}$ increases in $\mathrm{PM}_{10}$ (OR 1.40, 95\% CI: 1.17, 1.67) and $\mathrm{NO}_{2}$ (OR: 1.09, 95\% CI: 1.03, 1.38) (Eze et al., 2014). A 2011 Dutch study, however, found no association between $\mathrm{NO}_{2}$ and DM prevalence (Dijkema et al., 2011) while a 2008 casecontrol study of 7,634 individuals in two Canadian cities found $1 \mathrm{ppb}$ increases in $\mathrm{NO}_{2}$ to be significantly associated with DM prevalence in women (OR 1.04, 95\% CI: 1.00, 1.08) but not men (OR 0.99, 95\% CI: 0.95, 1.03) (Brook et al., 2008). Inconsistency in these findings may result from heterogeneity in underlying DM risk across the populations studied and/or differences in PM components/constituents in different geographic regions, with some areas having more diabetogenic exposures than others.

Interestingly, while relatively few studies have been conducted on $\mathrm{HbA1c}$, they are generally consistent in finding significant, positive associations with air pollution. Liu et al. (2016) observed an $0.08 \%$ increase in HbA1c level $\left(95 \%\right.$ CI: 0.06,0.10) per IQR $\left(41.1 \mu \mathrm{g} / \mathrm{m}^{3}\right)$ increase in $\mathrm{PM}_{2.5}$ exposures in 11,847 Chinese participants (Liu et al., 2016). A recent, large $(\mathrm{n}=73,117)$ Israeli study found that among diabetic patients, increased exposures to $\mathrm{PM}_{2.5}$ (IQR $22.3 \mu \mathrm{g} / \mathrm{m}^{3}$ ) was associated with increases in $\mathrm{HbA1c}$ of $2.93 \%$ (95\% CI: $0.35 \%$; $5.59 \%$ ) (Yitshak Sade et al., 2016). An earlier study in an elderly Taiwanese cohort $(\mathrm{n}=1,023)$ also observed significant increases in relative HbA1c associated with IQR (20.42 $\left.\mu \mathrm{g} / \mathrm{m}^{3}\right)$ increases in $\mathrm{PM}_{2.5}$ exposures $(2.10 \%, 95 \%$ CI: 1.50, 2.70) (Chuang et al., 2010). While no associations were found for $\mathrm{HbA1c}$, a recent study in a German population found significant associations between an IQR $\left(7.9 \mu \mathrm{g} / \mathrm{m}^{3}\right)$ increase in long-term $\mathrm{PM}_{2.5}$ exposure and markers of insulin resistance (Wolf et al., 2016). This finding is consistent with the proposed pathophysiologic mechanisms linking air pollution with perturbations in 
glycosylated hemoglobin levels. While the effects we observed for $\mathrm{PM}_{2.5}$ were of somewhat lesser magnitude than in many of these prior studies, this could be due to differences in underlying susceptibility to PM in these populations, differences in PM constituents, or the substantially larger average $\mathrm{PM}_{2.5}$ exposures in these studies (ranging between $22.3 \mu \mathrm{g} / \mathrm{m}^{3}$ and $\left.72.6 \mu \mathrm{g} / \mathrm{m}^{3}\right)$ as compared to ours $\left(10.4 \mu \mathrm{g} / \mathrm{m}^{3}\right)$.

Our two-pollutant models suggest that $\mathrm{NO}_{2}$ - perhaps as a marker of traffic related pollution - may be a more important predictor of $\mathrm{HbA1c}$, as the effect estimates for one-year moving averages of $\mathrm{NO}_{2}$ in non-diabetics $(0.8 \% \pm 0.2 \%, \mathrm{p}<0.01)$ and diabetics $(1.7 \% \pm 0.8 \%$, $\mathrm{p}<0.05)$ remain significant and only minimally changed while associations with one-year moving averages of $\mathrm{PM}_{2.5}$ were attenuated and insignificant. This is consistent with previous literature, which has found $\mathrm{NO}_{2}$ to be a stronger predictor of diabetes than is $\mathrm{PM}_{2.5}$ (Andersen et al., 2012; Brook et al., 2008; Coogan et al., 2012; Kramer et al., 2010). In two pollutant models of prevalent $\mathrm{DM}$, however, the association of $\mathrm{NO}_{2}$ was attenuated and borderline significant while $\mathrm{PM}_{2.5}$ was only minimally changed.

Our study has a number of limitations. First, we were unable to distinguish between type 1 and type 2 diabetes mellitus. However, given that type 2 diabetes mellitus accounts for up to $95 \%$ of diabetes mellitus, and all individuals in the current study were over 57 years of age, it is unlikely that substantial outcome misclassification occurred (ADA, 2013). Second, the change in method of HbA1c ascertainment between waves raises the possibility that $\mathrm{HbA1c}$ measurement precision or accuracy changed by wave. However, the two methods have been shown to be comparable with each other within the NSHAP cohort and with gold-standard venous sampling techniques in several studies, suggesting that our use of these measures in both waves is appropriate (Gregg et al., 2014; Lacher et al., 2013; Parkes et al., 1999). Third, exposure error for $\mathrm{NO}_{2}$ and to a lesser extent $\mathrm{PM}_{2.5}$ is probable. Our $\mathrm{PM}_{2.5}$ estimates account for spatial variability in outdoor $\mathrm{PM}_{2.5}$, with its accuracy and precision shown to be high in previous validation studies (Yanosky et al., 2014). $\mathrm{NO}_{2}$ estimates, in contrast, may have more associated measurement error given their basis on stationary ambient site measurements. However, our sensitivity analyses showing comparable effect estimates when $\mathrm{NO}_{2}$ exposure estimates were based on the nearest monitor within $60 \mathrm{~km}, 40 \mathrm{~km}, 20 \mathrm{~km}$ and $10 \mathrm{~km}$ suggest that exposure error from spatial variation did not significantly alter our findings. Additional exposure error, however, from differential penetration of pollutants from outdoor to indoor environments, indoor sources, and activity patterns, is likely.

These study limitations are balanced by a number of strengths. First, our study utilizes the NSHAP cohort which makes it among very few to investigate this association in a nationally representative sample of older Americans. Second, the availability of data on diabetic medication, medical history and $\mathrm{HbA} 1 \mathrm{c}$ levels significantly decreases the likelihood of outcome misclassification. Third, associations were robust to various more conservative exposure estimates (for $\mathrm{NO}_{2}$ ), various outcome definitions (for $\mathrm{DM}$ ) and a number of additional sensitivity analyses. Fourth, we have high quality exposure assessments and data on numerous relevant confounders available to minimize unmeasured confounding and potential bias. 


\title{
CONCLUSIONS
}

In a cohort of older men and women in the United States, $\mathrm{PM}_{2.5}$ and $\mathrm{NO}_{2}$ exposures were significantly associated with prevalence of diabetes and increased $\mathrm{HbA} 1 \mathrm{c}$ levels in nondiabetic and diabetic participants. These associations suggest that air pollution could be an important and ubiquitous risk factor for abnormal glucose metabolism and diabetes.

\section{Supplementary Material}

Refer to Web version on PubMed Central for supplementary material.

\section{Acknowledgments}

We thank Dr. Jeffrey Yanosky from the Pennsylvania State University for providing daily $\mathrm{PM}_{2.5}$ grid data.

FUNDING: This work was supported by NIEHS grant 1R01ES022657-01A1, with health and other covariate data obtained through NIH R01-AG021487, R37-AG030481, R01-AG033903, and R01-ES019168.

\author{
Abbreviations \\ DM Type 2 diabetes mellitus \\ HbA1c Glycosylated hemoglobin \\ $\mathrm{NO}_{2} \quad$ Nitrogen dioxide \\ $\mathbf{P M}_{2.5} \quad$ Particulate matter with an aerodynamic diameter of $\mathcal{2} .5 \mu \mathrm{m}$ \\ Ppb Parts per billion
}

\section{References}

Andersen ZJ, Raaschou-Nielsen O, Ketzel M, Jensen SS, Hvidberg M, Loft S, Tjonneland A, Overvad K, Sorensen M. Diabetes incidence and long-term exposure to air pollution: a cohort study. Diabetes care. 2012; 35:92-98. [PubMed: 22074722]

American Diabetes Association (ADA). Diagnosis and classification of diabetes mellitus. Diabetes care. 2013; 36:S67-S74. [PubMed: 23264425]

Brook RD, Jerrett M, Brook JR, Bard RL, Finkelstein MM. The relationship between diabetes mellitus and traffic-related air pollution. Journal of occupational and environmental medicine / American College of Occupational and Environmental Medicine. 2008; 50:32-38.

Chen H, Burnett RT, Kwong JC, Villeneuve PJ, Goldberg MS, Brook RD, van Donkelaar A, Jerrett M, Martin RV, Brook JR, Copes R. Risk of incident diabetes in relation to long-term exposure to fine particulate matter in Ontario, Canada. Environ Health Perspect. 2013; 121:804-810. [PubMed: 23632126]

Chuang KJ, Yan YH, Cheng TJ. Effect of Air Pollution on Blood Pressure, Blood Lipids, and Blood Sugar: A Population-Based Approach. Journal of Occupational and Environmental Medicine. 2010; 52:258-262. [PubMed: 20190657]

Centers for Disease Control and Prevention (CDC). National diabetes statistics report: estimates of diabetes and its burden in the United States, 2014. Atlanta, GA: US Department of Health and Human Services 2014; 2014.

Coogan PF, White LF, Jerrett M, Brook RD, Su JG, Seto E, Burnett R, Palmer JR, Rosenberg L. Air pollution and incidence of hypertension and diabetes mellitus in black women living in Los Angeles. Circulation. 2012; 125:767-772. [PubMed: 22219348] 
Dijkema MB, Mallant SF, Gehring U, van den Hurk K, Alssema M, van Strien RT, Fischer PH, Nijpels G, Stehouwer CD, Hoek G, Dekker JM, Brunekreef B. Long-term exposure to traffic-related air pollution and type 2 diabetes prevalence in a cross-sectional screening-study in the Netherlands. Environmental health : a global access science source. 2011; 10:76. [PubMed: 21888674]

Environmental Protection Agency (EPA), U.S.. US Environmental Protection Agency. Air Quality System; 2009. p. 2009

Eze IC, Schaffner E, Fischer E, Schikowski T, Adam M, Imboden M, Tsai M, Carballo D, von Eckardstein A, Künzli N, Schindler C, Probst-Hensch N. Long-term air pollution exposure and diabetes in a population-based Swiss cohort. Environment International. 2014; 70:95-105. [PubMed: 24912113]

Gregg FT, O’Doherty K, Schumm LP, McClintock MK, Huang ES. Glycosylated Hemoglobin Testing in the National Social Life, Health, and Aging Project. The Journals of Gerontology Series B: Psychological Sciences and Social Sciences. 2014; 69:S198-S204.

IMPROVE. Interagency Monitoring of Protected Visual Environments Homepage. King, G.L., 2008. The Role of Inflammatory Cytokines in Diabetes and Its Complications. Journal of Periodontology. 2013; 79:1527-1534.

Kramer U, Herder C, Sugiri D, Strassburger K, Schikowski T, Ranft U, Rathmann W. Traffic-related air pollution and incident type 2 diabetes: results from the SALIA cohort study. Environ Health Perspect. 2010; 118:1273-1279. [PubMed: 20504758]

Lacher DA, Berman LE, Chen TC, Porter KS. Comparison of dried blood spot to venous methods for hemoglobin A1c, glucose, total cholesterol, high-density lipoprotein cholesterol, and C-reactive protein. Clinica Chimica Acta. 2013; 422:54-58.

Liu C, Yang C, Zhao Y, Ma Z, Bi J, Liu Y, Meng X, Wang Y, Cai J, Kan H. Associations between long-term exposure to ambient particulate air pollution and type 2 diabetes prevalence, blood glucose and glycosylated hemoglobin levels in China. Environment international. 2016; 92:416421. [PubMed: 27148900]

Nallanathan, B., Williams, S., McDade, T., Lindau, ST. Dried Blood Spot Measurement of C-reactive protein in Wave I of the National Social Life, Health \& Aging Project (NSHAP), NORC and the. University of Chicago; 2008.

O’Neill MS, Veves A, Sarnat JA, Zanobetti A, Gold DR, Economides PA, Horton ES, Schwartz J. Air pollution and inflammation in type 2 diabetes: a mechanism for susceptibility. Occupational and environmental medicine. 2007; 64:373-379. [PubMed: 17182639]

Park SK, Adar SD, O’Neill MS, Auchincloss AH, Szpiro A, Bertoni AG, Navas-Acien A, Kaufman JD, Diez-Roux AV. Long-Term Exposure to Air Pollution and Type 2 Diabetes Mellitus in a Multiethnic Cohort. American journal of epidemiology. 2015; 181:327-336. [PubMed: 25693777]

Parkes J, Ray R, Kerestan S, Davis H, Ginsberg B. Prospective evaluation of accuracy, precision, and reproducibility of an at-home hemoglobin A1c sampling kit. Diabetes technology \& therapeutics. 1999; 1:411-419. [PubMed: 11474825]

Pearson JF, Bachireddy C, Shyamprasad S, Goldfine AB, Brownstein JS. Association between fine particulate matter and diabetes prevalence in the U.S. Diabetes care. 2010; 33:2196-2201. [PubMed: 20628090]

Poulsen P, Kyvik KO, Vaag A, Beck-Nielsen H. Heritability of type II (non-insulin-dependent) diabetes mellitus and abnormal glucose tolerance-a population-based twin study. Diabetologia. 1999; 42:139-145. [PubMed: 10064092]

Puett RC, Hart JE, Schwartz J, Hu FB, Liese AD, Laden F. Are particulate matter exposures associated with risk of type 2 diabetes? Environ Health Perspect. 2011; 119:384-389. [PubMed: 21118784]

Rajagopalan S, Brook RD. Air pollution and type 2 diabetes mechanistic insights. Diabetes. 2012; 61:3037-3045. [PubMed: 23172950]

Sade MY, Kloog I, Liberty IF, Katra I, Novack L, Novack V. Air pollution and serum glucose levels: a population-based study. Medicine. 2015; 94(27):e1093.doi: 10.1097/MD.0000000000001093 [PubMed: 26166095]

Sun Q, Yue P, Deiuliis JA, Lumeng CN, Kampfrath T, Mikolaj MB, Cai Y, Ostrowski MC, Lu B, Parthasarathy S. Ambient air pollution exaggerates adipose inflammation and insulin resistance in a mouse model of diet-induced obesity. Circulation. 2009; 119:538-546. [PubMed: 19153269] 
van Eeden SF, Tan WC, Suwa T, Mukae H, Terashima T, Fujii T, Qui D, Vincent R, Hogg JC.

Cytokines involved in the systemic inflammatory response induced by exposure to particulate matter air pollutants (PM(10)). American journal of respiratory and critical care medicine. 2001; 164:826-830. [PubMed: 11549540]

Waite, LJ., C, K., Dale, W., Huang, E., Laumann, EO., McClintock, M., et al. ICPSR34921-v1. Interuniversity Consortium for Political and Social Research; Ann Arbor, MI.: 2014. National Social Life, Health, and Aging Project (NSHAP): Wave 2 and Partner Data Collection.

Waite, LJ., Laumann, EO., Levinson, W., Lindau, ST., O’Muircheartaigh, CA. ICPSR20541-v6. Ann Arbor, MI: Inter-university Consortium for Political and Social Research; 2014. National Social Life, Health, and Aging Project (NSHAP): Wave 1. [distributor] 04-30

White IR, Royston P, Wood AM. Multiple imputation using chained equations: issues and guidance for practice. Statistics in medicine. 2011; 30:377-399. [PubMed: 21225900]

Wild S, Roglic G, Green A, Sicree R, King H. Global Prevalence of Diabetes. Diabetes care. 2004; 27:1047. [PubMed: 15111519]

Wolf K, Popp A, Schneider A, Breitner S, Hampel R, Rathmann W, Herder C, Roden M, Koenig W, Meisinger C, Peters A. Association Between Long-term Exposure to Air Pollution and Biomarkers Related to Insulin Resistance, Subclinical Inflammation, and Adipokines. Diabetes. 2016; 65:3314. [PubMed: 27605624]

Yanosky JD, Paciorek CJ, Laden F, Hart JE, Puett RC, Liao D, Suh HH. Spatio-temporal modeling of particulate air pollution in the conterminous United States using geographic and meteorological predictors. Environmental health : a global access science source. 2014; 13:63. [PubMed: 25097007]

Yitshak Sade M, Kloog I, Liberty IF, Schwartz J, Novack V. The Association Between Air Pollution Exposure and Glucose and Lipids Levels. The Journal of Clinical Endocrinology \& Metabolism. 2016; 101:2460-2467. [PubMed: 27218271]

Zoungas S, Chalmers J, Ninomiya T, Li Q, Cooper ME, Colagiuri S, Fulcher G, de Galan BE, Harrap S, Hamet P, Heller S, MacMahon S, Marre M, Poulter N, Travert F, Patel A, Neal B, Woodward M. Association of HbA1c levels with vascular complications and death in patients with type 2 diabetes: evidence of glycaemic thresholds. Diabetologia. 2012; 55:636-643. [PubMed: 22186981] 


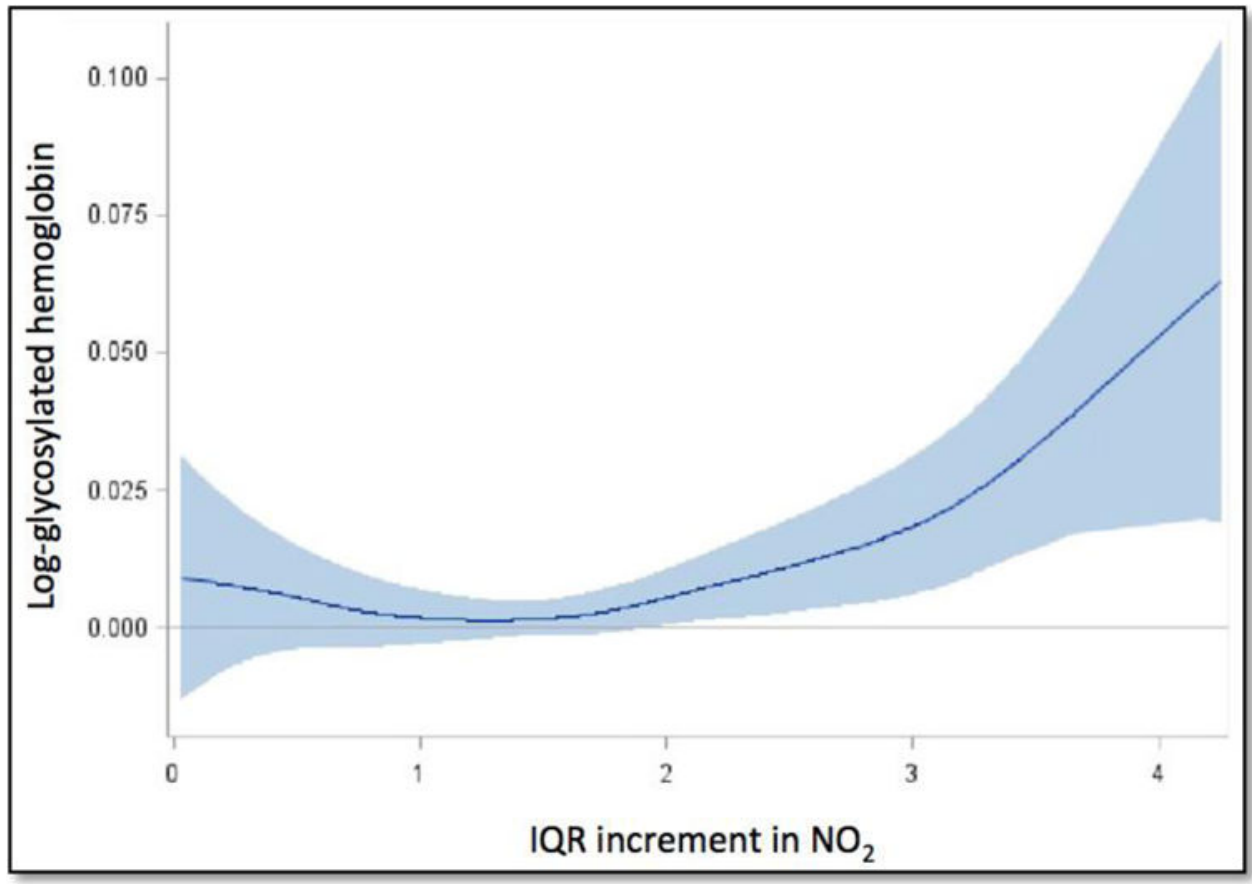

Figure 1.

Smoothing dose-response curve for association of an IQR increment of $\mathrm{NO}_{2}$ with logHbA1c in non-diabetic participants 


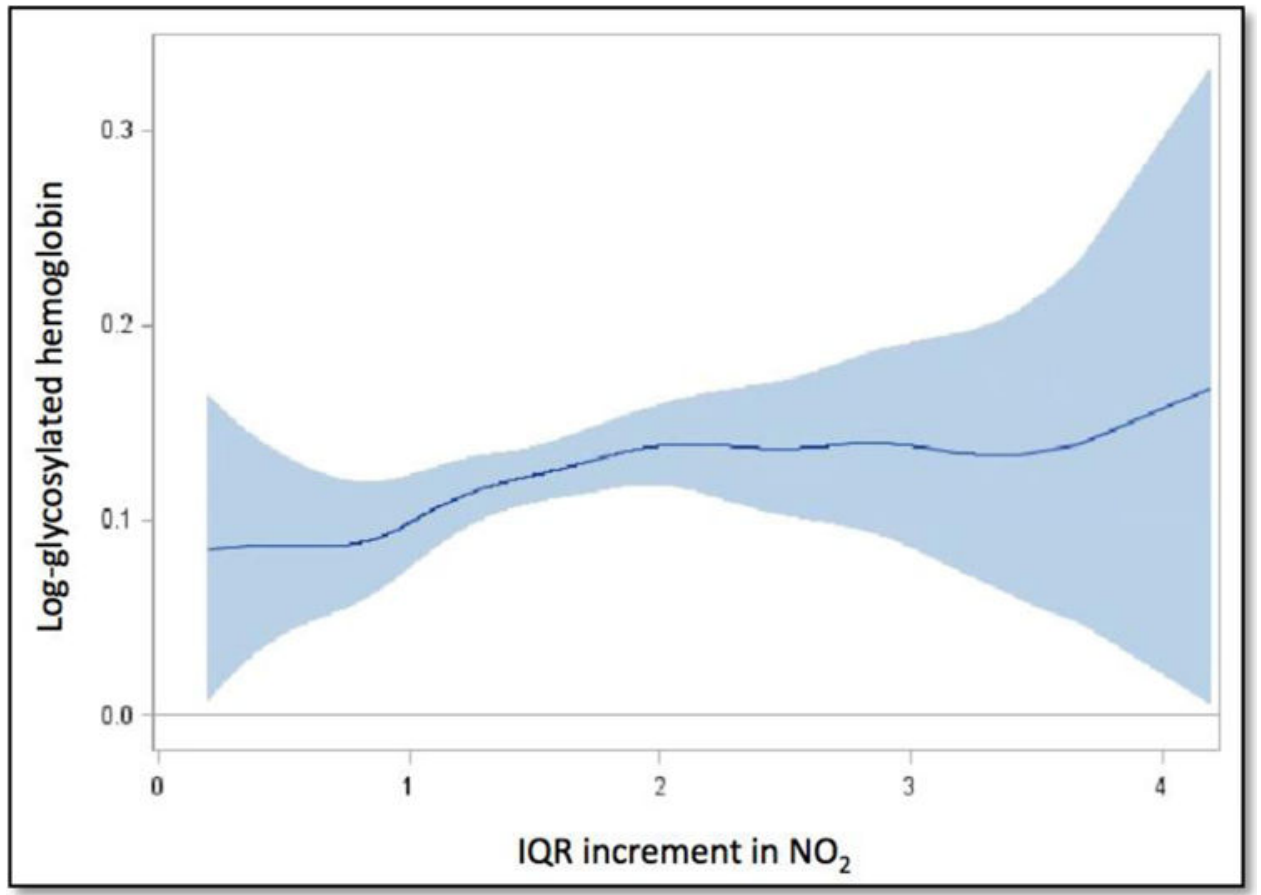

Figure 2.

Smoothing dose-response curve for association of an IQR increment of $\mathrm{NO}_{2}$ with log$\mathrm{HbA1c}$ in diabetic participants 


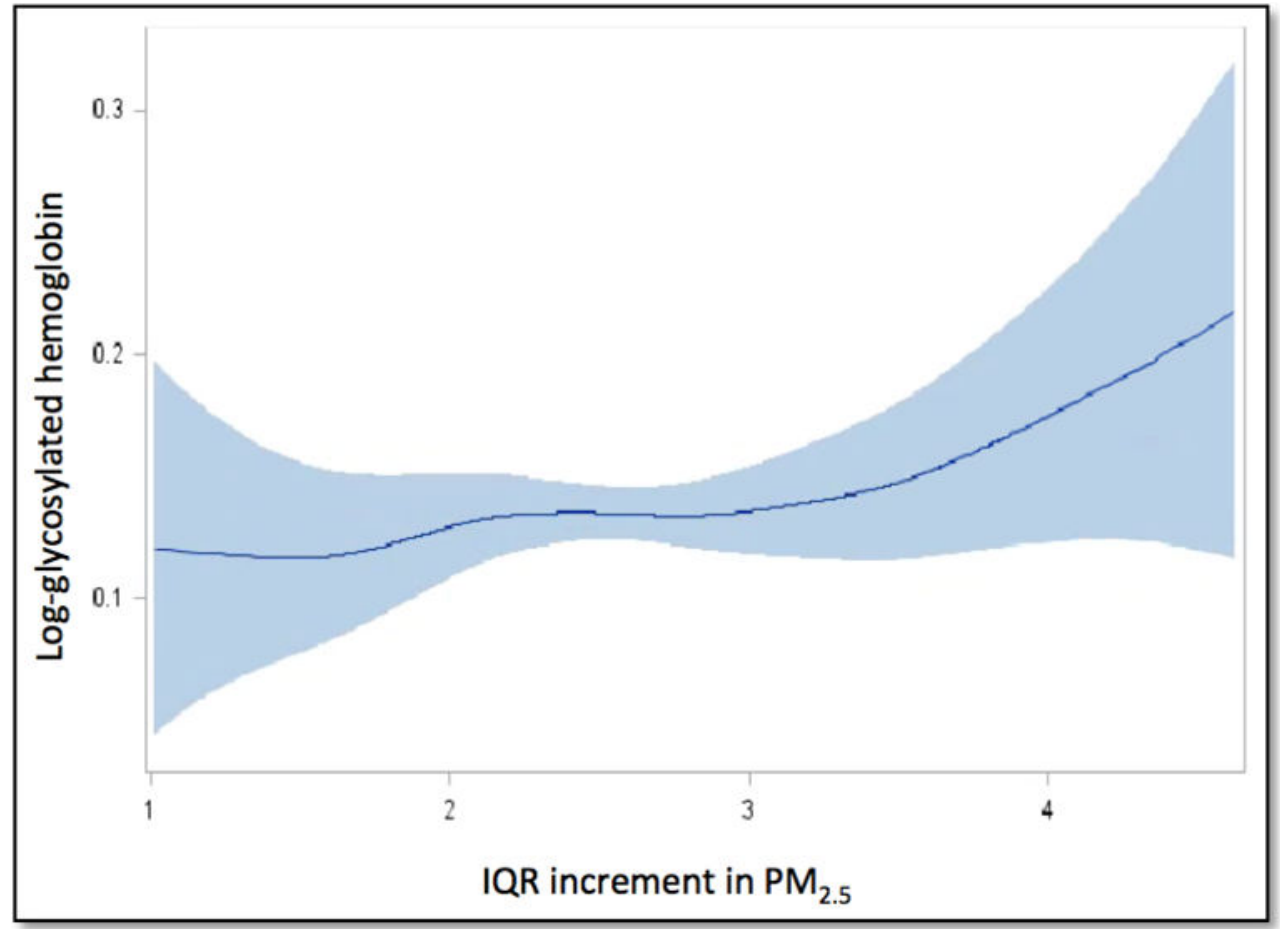

Figure 3.

Smoothing dose-response curve for association of an IQR increment of $\mathrm{PM}_{2.5}$ with logHbA1c in diabetic participants 
Table 1

Participant Characteristics: Total and by Diabetes Status at Study Entry

\begin{tabular}{|c|c|c|c|c|}
\hline Covariate & $\begin{array}{c}\text { Total } \\
(\mathrm{N}=\mathbf{4 1 2 1})\end{array}$ & $\begin{array}{c}\text { With DM } \\
(\mathbf{N}=916)\end{array}$ & $\begin{array}{c}\text { Without DM } \\
(\mathrm{N}=3205)\end{array}$ & p-value for difference ${ }^{b}$ \\
\hline Age (mean, SD) & $69.6(8.3)$ & $69.7(7.7)$ & $69.5(8.3)$ & 0.450 \\
\hline BMI kg/m² (mean, SD) & $29.2(6.2)$ & $31.9(6.8)$ & $28.5(5.8)$ & $<0.001$ \\
\hline Obese $^{c} \%$ & $35.7 \%$ & $55.2 \%$ & $33.4 \%$ & $<0.001$ \\
\hline Overweight ${ }^{d} \%$ & $34.7 \%$ & $30.1 \%$ & $36.0 \%$ & 0.001 \\
\hline Male \% & $46.3 \%$ & $49.0 \%$ & $45.6 \%$ & 0.064 \\
\hline \multicolumn{5}{|l|}{ DIABETES INDICATORS } \\
\hline $\mathrm{HbA1c} \%(\text { mean, } \mathrm{SD})^{e}$ & $6.0(1.1)$ & $7.0(1.2)$ & $5.6(1.1)$ & $<0.001$ \\
\hline Anti-diabetic Medication \% & $17.9 \%$ & $80.3 \%$ & - & - \\
\hline RACE & & & & $<0.001$ \\
\hline White $\%$ & $70.0 \%$ & $57.8 \%$ & $75.0 \%$ & \\
\hline Black \% & $15.8 \%$ & $24.5 \%$ & $13.4 \%$ & \\
\hline Hispanic $\%$ & $10.7 \%$ & $14.6 \%$ & $9.6 \%$ & \\
\hline Other $\%$ & $2.4 \%$ & $3.3 \%$ & $2.1 \%$ & \\
\hline \multicolumn{5}{|l|}{ SOCIOECONOMIC STATUS } \\
\hline Education level & & & & $<0.001$ \\
\hline$<$ High school \% & $21.5 \%$ & $29.5 \%$ & $19.3 \%$ & \\
\hline High school equivalent $\%$ & $25.7 \%$ & $25.8 \%$ & $25.7 \%$ & \\
\hline Some college $\%$ & $30.1 \%$ & $29.2 \%$ & $30.3 \%$ & \\
\hline College of greater $\%$ & $22.7 \%$ & $15.6 \%$ & $24.7 \%$ & \\
\hline Median household income (mean, SD) & $54,259(26,039)$ & $49,231(23,227)$ & $55,696(26,618)$ & $<0.001$ \\
\hline Percent census track below & $14.8 \%$ & $17.7 \%$ & $14.0 \%$ & $<0.001$ \\
\hline poverty line (mean, SD) & $(12.2 \%)$ & $(13.3 \%)$ & $(11.7 \%)$ & \\
\hline \multicolumn{5}{|l|}{ BEHAVIORAL VARIABLES } \\
\hline Current tobacco use & & & & 0.600 \\
\hline Yes $\%$ & $17.3 \%$ & $17.9 \%$ & $17.2 \%$ & \\
\hline No $\%$ & $82.7 \%$ & $82.1 \%$ & $82.8 \%$ & \\
\hline Physical Activity & & & & $<0.001$ \\
\hline$>3$ times/week \% & $55.6 \%$ & $46.6 \%$ & $58.1 \%$ & \\
\hline $1-2$ times per week $\%$ & $15.8 \%$ & $16.6 \%$ & $15.6 \%$ & \\
\hline $1-3$ times per month $\%$ & $7.2 \%$ & $7.5 \%$ & $7.1 \%$ & \\
\hline$<1$ time per month $\%$ & $7.0 \%$ & $8.0 \%$ & $6.7 \%$ & \\
\hline Never $\%$ & $14.2 \%$ & $21.1 \%$ & $12.3 \%$ & \\
\hline \multicolumn{5}{|l|}{ POLLUTANTS (mean, SD) } \\
\hline $\mathrm{PM}_{2.5}\left(\mu \mathrm{g} / \mathrm{m}^{3}\right)$ & $10.4(3.0)$ & $10.7(2.9)$ & $10.3(3.1)$ & $<0.001$ \\
\hline $\mathrm{NO}_{2}(\mathrm{ppb})$ & $13.7(6.6)$ & $13.7(6.8)$ & $13.7(6.6)$ & 0.921 \\
\hline
\end{tabular}


${ }^{a}$ DM defined as HbA1c $6.5 \%+$ and/or self-report of anti-diabetic medication use.

${ }^{b}$ Continuous and categorical variables were compared using t-tests and chi squared tests, respectively

$c^{c}$ Obese defined as BMI $30+\mathrm{kg} / \mathrm{m}^{2}$

$d_{\text {Overweight defined as BMI } 25-30 \mathrm{~kg} / \mathrm{m}^{2}}$

$e_{\text {The geometric mean and standard deviation are reported }}$ 


\section{Table 2}

Association between percent change in $\mathrm{HbA1c}$ and one-year moving averages of $\mathrm{PM}_{2.5}$ and $\mathrm{NO}_{2}$ for the full cohort and stratified by diabetes status ${ }^{a}$

\begin{tabular}{|c|c|c|c|c|}
\hline \multicolumn{5}{|l|}{ Full Cohort } \\
\hline Moving Average & \multicolumn{2}{|l|}{$\mathbf{P M}_{2.5} b$} & \multicolumn{2}{|l|}{$\mathrm{NO}_{2}^{c}$} \\
\hline 1 year \%-change (SE) & \multicolumn{2}{|l|}{$1.4 \% \pm 0.3 \%$} & \multicolumn{2}{|l|}{$2.0 \% \pm 0.3 \%$} \\
\hline \multicolumn{5}{|c|}{ Stratified by Diabetes Status } \\
\hline \multirow{2}{*}{ Moving Average } & \multicolumn{2}{|l|}{ Non-Diabetic } & \multicolumn{2}{|l|}{ Diabetic } \\
\hline & $\mathbf{P M}_{2.5} b$ & $\mathrm{NO}_{2}{ }^{c}$ & $\mathrm{PM}_{2.5} b$ & $\mathrm{NO}_{2}^{c}$ \\
\hline 1 year \%-change (SE) & $0.2 \%(0.2 \%)$ & $0.8 \%(0.2 \%)^{* * *}$ & $1.8 \%(0.6 \%)^{* *}$ & $2.0 \%(0.7 \%)^{* *}$ \\
\hline \multicolumn{5}{|l|}{ Trend Analysis $d$} \\
\hline Quartile 1 & - & - & - & - \\
\hline Quartile 2 & $-0.3 \%(0.4 \%)$ & $-0.4 \%(0.4 \%)$ & $-0.4 \%(1.1 \%)$ & $0.8 \%(1.3 \%)$ \\
\hline Quartile 3 & $-0.4 \%(0.4 \%)$ & $-0.0 \%(0.5 \%)$ & $1.2 \%(1.2 \%)$ & $2.9 \%(1.4 \%)^{*}$ \\
\hline Quartile 4 & $0.1 \%(0.4 \%)$ & $0.9 \%(0.5 \%)$ & $2.8 \%(1.2 \%)^{*}$ & $2.7 \%(1.5 \%)$ \\
\hline$P$ trend & 0.869 & 0.028 & 0.002 & 0.032 \\
\hline
\end{tabular}

Includes pollutant, BMI, age, sex, race, education, diabetic medication use, tobacco use, physical activity, region, urbanicity, census track data on median household income and percent of households living below the poverty line

$b_{\text {IQR 1-year PM2.5: } 3.9 \mu \mathrm{g} / \mathrm{m}^{3}}$

${ }^{c}$ Closest monitor within $80 \mathrm{~km}$; IQR 1-year $\mathrm{NO}_{2}: 8.6 \mathrm{ppb}$

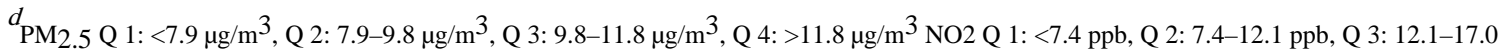
ppb, Q 4: >17.0 ppb

* $\mathrm{P}<0.05$

*** $\mathrm{P}<0.01$

**** $\mathrm{P}<0.001$ 
Table 3

Association between percent change in $\mathrm{HbA1c}$ and 2-5 year moving averages of $\mathrm{PM}_{2.5}$ and $\mathrm{NO}_{2}$ by diabetes status $^{a}$

\begin{tabular}{|c|c|c|c|c|}
\hline \multirow[b]{2}{*}{ Exposure Window } & \multicolumn{2}{|l|}{ Non-Diabetic } & \multicolumn{2}{|l|}{ Diabetic } \\
\hline & $\mathbf{P M}_{2.5}$ & $\mathrm{NO}_{2}^{b}$ & $\mathbf{P M}_{2.5}$ & $\mathrm{NO}_{2}^{b}$ \\
\hline 2 year $\%$-change (SE) & $0.3 \%(0.2 \%)$ & $\begin{array}{l}0.7 \%(0.2 \%)^{* *} \\
\mathrm{n}=3693\end{array}$ & $1.8 \%(0.6 \%)^{* *}$ & $\begin{array}{l}1.9 \%(0.7 \%)^{* * *} \\
\mathrm{n}=1472\end{array}$ \\
\hline 3 year \%-change (SE) & $0.3 \%(0.2 \%)$ & $\begin{array}{l}0.6 \%(0.2 \%)^{* *} \\
\mathrm{n}=3686\end{array}$ & $1.6 \%(0.5 \%)^{* *}$ & $\begin{array}{l}1.9 \%(0.7 \%) \text { ** } \\
\mathrm{n}=1470\end{array}$ \\
\hline 4 year $\%$-change (SE) & $0.3 \%(0.2 \%)$ & $\begin{array}{l}0.7 \%(0.2 \%)^{* * *} \\
\mathrm{n}=3661\end{array}$ & $1.3 \%(0.5 \%)^{*}$ & $\begin{array}{l}1.9 \%(0.7 \%)^{* *} \\
\mathrm{n}=1451\end{array}$ \\
\hline 5 year \% - change (SE) & $0.2 \%(0.2 \%)$ & $\begin{array}{l}0.7 \%(0.2 \%)^{* * *} \\
\mathrm{n}=3600\end{array}$ & $1.3 \%(0.5 \%)^{*}$ & $\begin{array}{l}1.7 \%(0.6 \%)^{* * *} \\
\mathrm{n}=1451\end{array}$ \\
\hline
\end{tabular}

\footnotetext{
Includes pollutant, BMI, age, sex, race, education, diabetic medication use tobacco use, physical activity, region, urbanicity, census track data on median household income and percent of households living below the poverty line

$b_{\text {Closest monitor within } 80 \mathrm{~km}}$

P $<0.05$

** $\mathrm{P}<0.01$

**** $\mathrm{P}<0.001$
}

IQR PM: 1 year: 3.9, 2 year: 3.7, 3 year: $3.6,4$ year: $3.7,5$ year: 3.8

IQR $\mathrm{NO}_{2}: 1$ year: 8.6, 2 year: $8.1,3$ year: $8.2,4$ year: $8.2,5$ year: 8.3 


\section{Table 4}

Association between DM ${ }^{a}$ prevalence and 1 to 5 year moving averages of $\mathrm{PM}_{2.5}$ and $\mathrm{NO}_{2}{ }^{b}$

\begin{tabular}{|c|c|c|}
\hline \multirow[b]{2}{*}{ Exposure Window } & \multicolumn{2}{|l|}{ POR (95\% CI) } \\
\hline & $\mathbf{P M}_{2.5}$ & $\mathrm{NO}_{2}^{c}$ \\
\hline 1 year & $1.35(1.19,1.53)^{* * *}$ & $1.27(1.10,1.48)^{* *}$ \\
\hline 2 year & $1.30(1.16,1.46){ }^{* *}$ & $1.25(1.09,1.43)^{* *}$ \\
\hline 3 year & $1.28(1.14,1.44) * *$ & $1.23(1.08,1.40)^{* *}$ \\
\hline 4 year & $1.27(1.13,1.43) * *$ & $1.20(1.05,1.38)^{* *}$ \\
\hline 5 year & $1.27(1.13,1.42){ }^{* *}$ & $1.22(1.07,1.39)^{* *}$ \\
\hline
\end{tabular}

${ }^{a} \mathrm{DM}$ defined as HbA1c $6.5 \%+$ and/or self-report of anti-diabetic medication use.

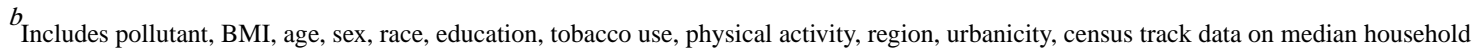
income and percent of households living below the poverty line

${ }^{c}$ Closest monitor within $80 \mathrm{~km}$

P $<0.05$

*** $<0.01$

**** $\mathrm{P}<0.001$

POR is prevalence odds ratio

IQR PM: 1 year: 3.9, 2 year: 3.7, 3 year: 3.6, 4 year: 3.7, 5 year: 3.8

IQR NO2: 1 year: 8.6, 2 year: 8.1, 3 year: 8.2, 4 year: $8.2,5$ year: 8.3 